Document downloaded from:

http://hdl.handle.net/10251/58843

This paper must be cited as:

Navarro Esbri, J.; Mendoza Miranda, JM.; Mota Babiloni, A.; Barragán Cervera, A.; Belman Flores, JM. (2013). Experimental analysis of R1234yf as a drop-in replacement for R134a in a vapor compression system. International Journal of Refrigeration. 36(3):870-880. doi:10.1016/j.jirefrig.2012.12.014.

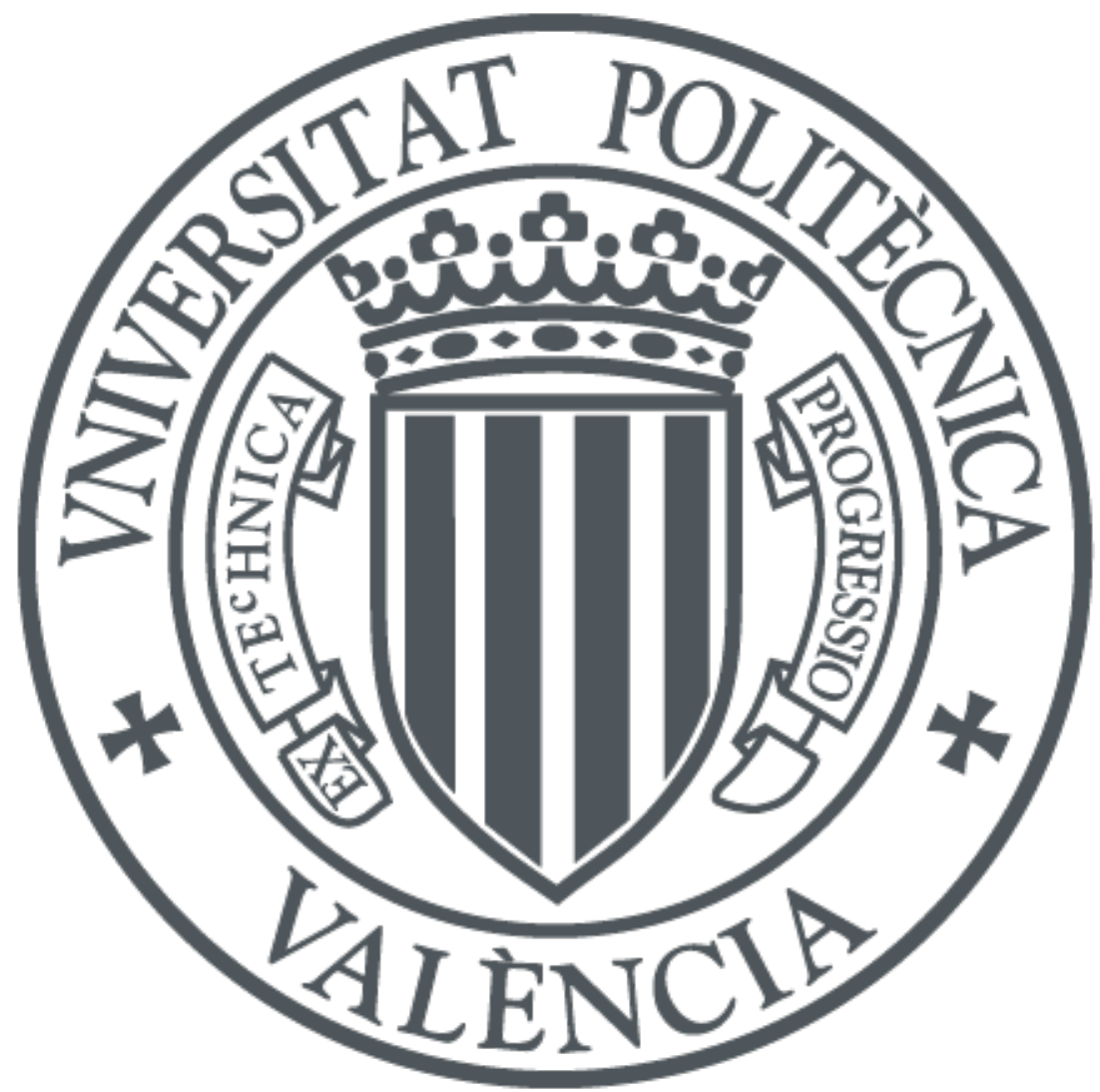

The final publication is available at

http://dx.doi.org/10.1016/j.jjefrig.2012.12.014

Copyright Elsevier

Additional Information 


\title{
Experimental analysis of R1234yf as a drop-in replacement for R134a in a vapor compression system.
}

J. Navarro-Esbrî, ${ }^{a,}$, J.M. Mendoza-Miranda ${ }^{\mathrm{b}}$, A. Mota-Babiloni ${ }^{\mathrm{a}}$, A. Barragán-Cervera ${ }^{\mathrm{a}}$, J.M. Belman-Flores ${ }^{\mathrm{b}}$.

${ }^{a}$ Department of Mechanical Engineering and Construction, Campus de Riu Sec s/n, University Jaume I, E12071, Castellón, Spain.

${ }^{b}$ Engineering Division, Campus Irapuato-Salamanca, University of Guanajuato. Carr. Salamanca-Valle de Santiago km 3.5+1.8 km. Comunidad de Palo Blanco. C.P. 36885, Salamanca, Gto., Mexico.

\begin{abstract}
This paper presents an experimental analysis of a vapor compression system using R1234yf as a drop-in replacement for R134a. In this work, we compare the energy performance of both refrigerants, R134a and R1234yf, in a monitored vapor compression system under a wide range of working conditions. So, the experimental tests are carried out varying the condensing temperature, the evaporating temperature, the superheating degree, the compressor speed, and the internal heat exchanger use. Comparisons are made taking refrigerant R134a as baseline, and the results show that the cooling capacity obtained with R1234yf in a R134a vapor compression
\end{abstract}

\footnotetext{
${ }^{*}$ Corresponding Author:

Tel: +34 964728137; fax: +34 964728106.

E-mail address: navarroj@emc.uji.es
} 
system is about $9 \%$ lower than that obtained with R134a in the studied range. Also, when using R1234yf, the system shows values of COP about 19\% lower than those obtained using R134a, being the minor difference for higher condensing temperatures. Finally, using an internal heat exchanger these differences in the energy performance are significantly reduced.

KEYWORDS: Drop-in, R1234yf, R134a, Vapor compression system, internal heat exchanger, low GWP.

NOMENCLATURE

\begin{tabular}{|ll}
\hline COP & Coefficient of performance \\
$C_{p}$ & Specific heat $\left(\mathrm{kJ} \mathrm{kg}^{-1} \mathrm{~K}^{-1}\right)$ \\
$f$ & Compressor drive frequency $(\mathrm{Hz})$ \\
$G R$ & Superheating degree $(\mathrm{K})$ \\
$G S$ & Subcooling degree $(\mathrm{K})$ \\
$h$ & Specific enthalpy $\left(\mathrm{kJ} \mathrm{kg}^{-1}\right)$ \\
$\dot{m}$ & Mass flow rate $\left(\mathrm{kg} \mathrm{s}^{-1}\right)$ \\
$N$ & Compressor rotation speed $(\mathrm{rpm})$ \\
$P$ & Pressure $(\mathrm{kPa})$ \\
$Q_{o}$ & Heat transfer rate $\left(\mathrm{kW}^{2}\right)$ \\
$S$ & Specific entropy $\left(\mathrm{kJ} \mathrm{kg} \mathrm{K}^{-1}\right)$ \\
$T$ & Temperature $(\mathrm{K})$
\end{tabular}




\begin{tabular}{|ll|}
\hline$V_{G}$ & Geometric volume $\left(\mathrm{m}^{3}\right)$ \\
$\eta_{v}$ & Volumetric efficiency \\
$\rho_{\text {asp }}$ & Density at suction $\left(\mathrm{kg} \mathrm{m}^{-3}\right)$ \\
Subscripts & \\
brine & Propileneglycol brine \\
$\mathrm{k}$ & Condensation \\
o & Evaporation \\
pi & Evaporator inlet (brine side) \\
po & Evaporator outlet (brine side) \\
ref & Refrigerant \\
\hline
\end{tabular}

\section{INTRODUCTION}

During 1900's, chlorofluorocarbons (CFCs) and hydrochlorofluorocarbons (HCFCs) were extensively used in refrigeration and air conditioning vapor compression systems. When their ozone-depleting potential became recognized, the Montreal Protocol was adopted by many nations to begin the phase out of both CFCs and HCFCs (UNEP, 1987). So, hydrofluorocarbons (HFCs) were developed as long term alternative to substitute CFCs and HCFCs, and while they were non-ozone depleting, they did have large global warming potential (GWP). In 1997, HFCs were considered as greenhouse gases (GHGs) and currently they are target compounds for GHG 
emission reduction under the Kyoto Protocol (GCRP, 1997). In this way, the growing international concern over relatively high GWP refrigerants has motivated the study of low GWP alternatives for HFCs in vapor compression systems. One of those refrigerants is R134a, with a GWP (100 years) of 1430, extensively used in refrigeration and air conditioning (banned in Europe for new mobile air conditioners according to Directive 2006/40/EC). The main candidates to replace R134a in vapor compression systems are natural refrigerants like ammonia, carbon dioxide or hydrocarbons (HC) mixtures; low GWP HFCs, highlighting R32 and R152a; and HFO, specifically R1234yf, developed by Honeywell and DuPont (Spatz and Minor, 2008).

Among the various studies of hydrocarbons mixtures using propane (R290), those using butane (R600) and isobutane (R600a) have given good results in comparison with R134a. The best performance is reached with the mixture propane/butane/isobutane (50/40/10 in mass) (Wongwises, et al., 2006). The main disadvantage of the implementation of hydrocarbons mixtures is their flammability (BSI, 2004). For the case of drop-in in domestic refrigeration with medium-class flammability refrigerants, like R152a and R32, the average COP obtained using $\mathrm{R} 152 \mathrm{a}$ is higher than the one using R134a, while the average COP of R32 is lower than the one using R134a (Bolaji, 2010). R1234yf has been proposed as a replacement for R134a in mobile air conditioning systems (Spatz and Minor, 2008), and its similar thermophysical properties makes R1234yf a good choice to replace R134a in other applications of refrigeration and air conditioning.

Focusing on R1234yf, this refrigerant does not contain chlorine, and therefore its ODP is zero (WMO, 2007), and its GWP is as low as 4 (Nielsen et al., 2007; Papadimitriou et al., 2008). About security characteristics, R1234yf has low toxicity, similar to R134a, and mild flammability, significantly less than R152a (Koban, 2009). Analyzing other environmental 
effects of R1234yf, in the case that this refrigerant would be released into the atmosphere, it is almost completely transformed to the persistent trifluoroacetic acid (TFA), and the predicted consequences of some studies of using R1234yf (Henne et al., 2012) show that future emissions would not cause significant increase in TFA rainwater concentrations.

Several works can be found in the literature presenting theoretical studies to determine the feasibility of direct substitution (or with slight modifications) using R1234yf in facilities working with R134a (Akasaka et al., 2010), being most of them based on mobile air conditioning systems. Lee et al. (2012), measured theoretically the drop-in performance of R1234yf in a simple bench tester and examined the possibility of substituting R134a in mobile air conditioning systems. Zilio et. al. (2011) experimented with R1234yf in a typical R134a European automotive air conditioning system with some modifications. Bryson et. al. (2011) tested a car air conditioning system using refrigerants R152a and R1234yf to replace R134a.

In other refrigeration and air conditioning applications there is also a trend of using low GWP refrigerants as alternative and, furthermore, future legislation will probably encourage a greater use of them. Particularly, it has been studied the possibility of replacing R134a and R410A, which have a GWP of 1890, by other low GWP refrigerants. This has been done following the established trend in the automotive industry of replacing high GWP refrigerants. Reasor et. al. (2010) evaluated the possibility of R1234yf to be a drop-in replacement for a pre-designed system with R134a or R410A, comparing thermophysical properties and simulating operational conditions. Leck (2010) discussed R1234yf, and other new refrigerants developed by DuPont, as replacement for various high-GWP refrigerants. Endoh et al. (2010) modified a room air conditioner that had been using R410A to meet the properties of R1234yf, and also evaluated the cycle performance capacity. Okazaki et al. (2010) studied the performance of a room air 
conditioner using R1234yf and R32/R1234yf mixtures, which was originally designed for R410A, with both the original and modified unit.

The aim of this work is to present an experimental study of R1234yf as a drop-in replacement for refrigerant R134a in a vapor compression system in a wide range of working conditions. An energetic characterization with both refrigerants is carried out using as main performance parameters the cooling capacity, the compressor volumetric efficiency, the compressor power consumption, and the COP. This experimental analysis has been executed varying the condensing temperature, the evaporating temperature, the superheating degree, the compressor drive frequency, and the use of an internal heat exchanger. The results obtained with R134a are taken as baseline for comparison.

The rest of the paper is organized as follows. In section 2, the refrigeration test bench used to obtain the experimental data is described. In section 3 , the experimental procedure and the data validation considerations are briefly exposed. In section 4, the experimental results are presented and discussed. Finally, in section 5, the main conclusions of the paper are summarized.

\section{EXPERIMENTAL REFRIGERATION PLANT}

In this work, the tests are carried out in an experimental test facility that consists of a vapor compression system, Fig. 1, working with refrigerants R134a and R1234yf. The test bench is completed with two secondary circuits: condensing water loop and load simulation system, which allow changing the heat load as well as the evaporating and condensing conditions. The 
condenser water loop consists of a closed-type cooling system, which allows controlling the temperature of the water and its mass flow rate. The load simulation system also regulates the secondary coolant (water/propylene glycol brine) temperature through a set of immersed PID controlled electrical resistances; meanwhile its mass flow rate can be adjusted using a variable speed pump.

Fig. 1. Schematic diagram of the test bench.

The main components of the vapor compression plant are: an open type reciprocating compressor, a shell-and-tube condenser (with refrigerant flowing along the shell and the water inside the tubes), an internal tube-in-tube heat exchanger (IHX), a set of expansion valves, and a shell-and-tube evaporator, where the refrigerant flows inside the tubes and a brine waterpropylene glycol (65/35\% by volume) is used as secondary fluid flowing along the shell.

The thermodynamic states of the refrigerant are obtained measuring pressure and temperature at the inlet and outlet of each basic component of the test facility, using eleven K-type thermocouples and eight piezoelectric pressure gauges. The temperature sensors are calibrated in our own laboratory using certified references, obtaining an uncertainty of $\pm 0.3 \mathrm{~K}$; while the pressure transducers, within a range of $0-3000 \mathrm{kPa}$, have an uncertainty of $\pm 0.1 \%$ of the full scale range. The refrigerant mass flow rate is measured by a Coriolis mass flow meter located at the liquid line, with a certified accuracy within $\pm 0.22 \%$ of the reading. The compressor electric consumption is measured using a digital wattmeter, with a calibration specified uncertainty of $\pm 0.5 \%$; and the compressor rotation speed is also measured using a capacitive sensor (with an 
uncertainty of $\pm 1 \%$ ). The thermodynamic properties are calculated using REFPROP (Lemmon, et al., 2007).

The volumetric flow rates of the secondary fluids are measured using two electromagnetic flow meters. Immersed thermocouples (with an accuracy of $\pm 0.1 \mathrm{~K}$ ) are mounted in order to obtain secondary fluid temperatures.

Finally, all the measurements are gathered with a National Instruments data acquisition system and monitored through a Personal Computer.

\section{EXPERIMENTAL PROCEDURE}

\subsection{Experimental steady-state test.}

In order to obtain the experimental data to characterize the energy performance of the test bench using both refrigerants, 104 steady-state tests are carried out in a wide range of operating conditions, as shown in Table 1. The condensing and evaporating pressure/temperature ranges for the experimental tests are presented in Fig. 2.

Table 1. Range of operating conditions in the experimental tests.

Fig. 2. Experimental test variation range. 
The process of selecting a steady state consists of taking a time period of twenty minutes, with a sample period of 0.5 seconds, in which the condensing and evaporating pressure are within an interval of $\pm 2.5 \mathrm{kPa}$. Furthermore, in these tests all the temperatures are within $\pm 0.5 \mathrm{~K}$ and refrigerant mass flow rate is within $\pm 0.0005 \mathrm{~kg}-\mathrm{s}^{-1}$. Then, once a steady state is achieved (with 2400 direct measurement), the data used as a steady state test are obtained averaging over a time period of five minutes (600 measurements). Fig. 3 shows the variation about the mean value in a random test for the condensing pressure, the evaporating pressure, the superheating degree and the refrigerant mass flow rate.

Fig. 3. Fluctuation of operating parameters in a random steady-state test. (a) Condensing pressure, (b) evaporating pressure, (c) superheating degree, (d) refrigerant mass flow rate. 


\subsection{Propagation of errors in the estimated parameters}

To have a general understanding on the associated uncertainty with the parameters calculated from measurements, the characteristic parameters uncertainty propagation is obtained using the RSS method (Taylor, 1997), Table 2.

Table 2. Uncertainties for calculated parameters.

\subsection{Data validation}

In order to check the accuracy of the measurements, a comparison between the heat load removed by the refrigerant and the heat supplied by the brine at the evaporator is carried out. So, Fig. 4 shows a comparison between the cooling capacity measured at the refrigerant side and at the propylene glycol brine side, including all the experimental tests used in this work with both refrigerants.

Fig.4. Cooling capacity at the evaporator (comparing refrigerant side and brine side).

The cooling capacity at the refrigerant side is obtained as the product of the experimental refrigerant mass flow rate $\left(\dot{m}_{\text {ref }}\right)$ and the refrigerating effect, computed from the measured 
refrigerant thermodynamic states at the evaporator inlet $\left(h_{5}\right)$ and outlet $\left(h_{6}\right)$. So, the cooling capacity is expressed as:

$Q_{o, r e f}=\dot{m}_{r e f}\left(h_{6}-h_{5}\right)$

The cooling capacity at the brine side is obtained using the measured brine flow rate and the temperatures at the evaporator inlet $\left(T_{p i}\right)$ and outlet $\left(T_{p o}\right)$ :

$Q_{o, \text { brine }}=\dot{m}_{\text {brine }} C_{p, \text { brine }}\left(T_{p i}-T_{p o}\right)$

\section{RESULTS AND DISCUSSION}

\subsection{Theoretical expected results}

In order to analyze the influence of the operating parameters (evaporating temperature, condensing temperature, superheating degree, and the use of IHX) on the cooling capacity and the COP, a previous simple theoretical study is carried out. In this theoretical study the following assumptions are made:

- the evaporator outlet temperature is established as the evaporation temperature plus the superheating degree (with two levels of superheating degree: $5 \mathrm{~K}$ and $10 \mathrm{~K}$ ),

- there pressure drops are neglected,

- the compression process is assumed isentropic,

- volumetric efficiency of 1 , 
- there is no heat transfer to the surroundings,

- a subcooling degree of $2 \mathrm{~K}$ is considered at the condenser outlet

- the possibility of using an IHX (efficiency of 50\%) is considered

- isenthalpic process is considered at the expansion valve.

The refrigerant mass flow rate is calculated as follows:

$\dot{m}_{\text {ref }}=\rho_{\text {asp }} V_{G}\left(\frac{N}{60}\right)$

where $N$ is the compression rotation speed in rpm, and $\rho_{a s p}$ is the density of the refrigerant at the compressor suction.

The cooling capacity is defined as the product of the refrigerant mass flow rate and the refrigerating effect (enthalpy difference between evaporator outlet and inlet):

$Q_{o}=\left(\rho_{a s p} \eta_{v} V_{G}\right)\left(\frac{N}{60}\right)\left(h_{6}-h_{5}\right)$

The theoretical COP only depends on thermodynamic states at the inlet and outlet of the evaporator and the compressor, and is defined as:

$\mathrm{COP}=\frac{h_{6}-h_{5}}{h_{1}-h_{6}}$

where $h_{1}$ is the specific enthalpy at compressor discharge, obtained by using the condensation pressure and specific entropy at the inlet of the compressor $\left(s_{6}\right)$. 
Fig. 5. Theoretical cooling capacity variation versus evaporating temperature $T_{o}$ : (a) varying condensing temperature, (b) with and without IHX (c) varying superheating degree, (d) comparing R1234yf with IHX and R134a without IHX.

Fig. 6. Theoretical COP variation versus evaporation temperature $T_{o}$ : (a) varying condensing temperature, (b) with and without IHX (c) varying superheating degree, (d) comparing R1234yf with IHX and R134a without IHX.

Figures 5 and 6 show the variations of the theoretical cooling capacity and COP using both refrigerants varying the operating pressures, the superheating degree and with and without IHX. These theoretical results reveal that the cooling capacity with R1234yf would be 8-11\% lower than using R134a (Fig. 5a), meanwhile the COP is also about 5-10\% lower (Fig. 6a). When an IHX (efficiency $=50 \%$ ) is used with both refrigerants, the difference between the theoretical cooling capacity and COP obtained with R134a and R1234yf is reduced, with a difference about 3-6\% in cooling capacity and 2-4\% in COP (Fig. $5 \mathrm{~b}$ and Fig. 6b). It is also observed that the difference between the theoretical cooling capacity and COP using both refrigerants is slightly reduced when the condensing temperature is decreased, and having no significant influence the superheating degree (Fig. 5c and Fig. 6c). The differences in the energy performance are practically total reduced when an IHX is used with R1234yf compared with theoretical results using R134a without IHX. 


\subsection{Experimental Results}

This section describes the experimental results obtained in the test bench using R1234yf and R134a, showing the main energy performance parameters: cooling capacity, compressor power consumption, and COP.

Fig. 7. Experimental cooling capacity variation regarding evaporating temperature $T_{o}$ varying: (a) condensing temperature, (b) use of IHX, (c) superheating degree, (d) compressor drive frequency.

Fig. 7 presents the obtained results for the cooling capacity using R134a and R1234yf. Experimental tests show that the cooling capacity using R1234yf in a drop-in replacement is about 9\% lower than using R134a. This difference remains approximately constant when the evaporating and condensing temperature are varied (Fig. 7a). It can also be seen that the difference between the cooling capacities using both refrigerants diminishes when an IHX is used (Fig. 7b), being this difference about 9-10\% without IHX and about $7 \%$ when an IHX is used (despite the IHX efficiency is about 20\%). Furthermore, comparing the values of cooling capacity obtained using R1234yf with IHX with those obtained using R134a without IHX, the difference is reduced until about $5 \%$.

Observing Fig. 7c, it can be extracted that there is not a significant influence of the superheating degree on the difference of cooling capacities obtained with both refrigerants. Analyzing Fig. 7d, it can be seen that the cooling capacity increases when compressor drive frequency is increased. 
When the compressor frequency increases from $35 \mathrm{~Hz}$ to $50 \mathrm{~Hz}$, there is an increase in the cooling capacity using R134a about 19-45\%, similar to that obtained using R1234yf (27-40\%), maintaining the difference of the values of cooling capacity obtained using both refrigerants approximately constant.

Fig. 8. R134a and R1234yf volumetric efficiency versus compression ratio.

In Fig. 8 the influence of the compression ratio on the compressor volumetric efficiency using both refrigerants is presented. It has to be noted that the compressor volumetric efficiency using R1234yf is 5\% lower compared with that using R134a. Furthermore, in this figure, one can observe that the dispersion obtained for the R1234yf volumetric efficiency is larger than that presented by R134a data. This fact is motivated by the larger influence of the compressor speed on the volumetric efficiency when R1234yf is used, which can be partly explained by higher pressure drops using this refrigerant.

Fig. 9. Experimental power consumption $\left(P_{c}\right)$ regarding evaporation temperature $T_{o}$ varying: (a) condensing temperature, (b) superheating degree, (c) compressor drive frequency.

Fig. 9 presents the compressor power consumption using both refrigerants at different working conditions. Fig. 9a presents that the power consumption obtained using R1234yf, when the operating pressures are changed in the test range, is between 1-2\% (for a condensing temperature 
of $33.15 \mathrm{~K}$ ) and $18-27 \%$ (for a condensing temperature of $313.15 \mathrm{~K}$ ) higher than that obtained using R134a. So, the minimum difference in the power consumption is given for high condensing temperatures, when the refrigerant mass flow rate is low and the pressure drops are also low. Furthermore, it can be seen that the measured power consumption decreases when the condensing temperature decreases, mainly due to a reduction in the compression ratio, being the slope of the power consumption reduction presented by R134a sharper than the one presented by R1234yf.

Analyzing the influence of the superheating degree on the compressor power consumption, Fig. $9 \mathrm{~b}$, it is observed a decrease in the power consumption when the superheating degree increases from $5 \mathrm{~K}$ to $10 \mathrm{~K}$, remaining the difference between both refrigerants approximately constant. Finally, analyzing the influence of the compressor frequency, Fig. 9c, we can see that the difference between both refrigerants power consumption at $35 \mathrm{~Hz}$ is lower than that observed at $50 \mathrm{~Hz}$. This fact is due to the higher pressure drops using R1234yf in comparison with those presented when using R134a. So, when the compressor frequency drive increases from $35 \mathrm{~Hz}$ to $50 \mathrm{~Hz}$, the pressure drops increases about 67\% using R1234yf, meanwhile pressure drops using R134a only increases about $38 \%$.

Fig. 10. Experimental COP variation regarding evaporation temperature $T_{o}$ varying: (a) condensing temperature, (b) use of IHX, (c) superheating degree, (d) compressor drive frequency. 
Fig. 10 shows the variation of the COP with the operating parameters. It is observed that the COP obtained using R1234yf is about 5-27\% lower than that observed when using R134a when the operating pressures are changed in the test range (Fig. 10a). This difference in the values of the COP using both refrigerants is lower for higher condensing temperatures, being about $8 \%$ for condensing temperatures of $333.15 \mathrm{~K}$ and about $25 \%$ for condensing temperatures of $313.15 \mathrm{~K}$. It can be also seen that the IHX has a significant influence on the COP differences between both refrigerants (Fig. 10b). So, the values of the COP for R1234yf are 11-24\% lower than those obtained for R134a when the IHX is not used and about 6-17\% when the IHX is used.

Analyzing the influence of the superheating degree on the COP, Fig. 10c, it can be observed that the difference about the values of the COP obtained using R134a and R1234yf increases when the superheating degree rises. The influence of the compressor drive frequency on the COP is shown in Fig. 10d, where it can be seen that the difference between the COP obtained using R1234yf and using R134a is increased when the compressor speed augments, again mainly due to higher pressure drops using R1234yf. This fact is given because the higher increment in compressor power consumption using R1234yf, in comparison with the increment presented by R134a, when the compressor frequency is raised from $35 \mathrm{~Hz}$ to $50 \mathrm{~Hz}$.

Finally, Table 3 summarizes the results presented in figures 7, 9 and 10. This table shows the relative differences of the main energy parameters analyzed using R134a and R1234yf in the test range.

Table 3. Experimental variation for cooling capacity, compressor power consumption and COP taking R134a as baseline. 


\section{CONCLUSIONS}

In this paper, an experimental analysis of a vapor compression system using R1234yf as a dropin replacement for $\mathrm{R} 134 \mathrm{a}$ has been presented. In order to obtain a wide range of working conditions a total of 104 steady state tests have been carried out. The tests have been performed varying the condensing pressure, evaporating pressure, superheating degree, the compressor speed and the IHX use.

The energetic comparison is performed on the basis of the cooling capacity, the volumetric efficiency, the compressor power consumption, and the COP. The main conclusions of this paper can be summarized as follows.

- The cooling capacity of R1234yf used as a drop-in replacement in a R134a refrigerant facility is about $9 \%$ lower than that presented by $\mathrm{R} 134 \mathrm{a}$ in the test range. This difference in the values of cooling capacity obtained with both refrigerants decreases when the condensing temperature increases and when an IHX is used.

- The volumetric efficiency using R1234yf is about 5\% lower in comparison with that obtained with R134a. Furthermore, the compressor volumetric efficiency using R1234yf shows a greater dependence on the compressor speed.

- The values of the COP obtained using R1234yf are between 5\% and 30\% lower than those obtained with R134a. Here, it is observed that when the condensing temperature 
raises from $313.15 \mathrm{~K}$ to $333.15 \mathrm{~K}$ this difference decreases from $25 \%$ until $8 \%$, even more in the case of using an IHX.

Finally, it can be concluded, from the experimental results, that the energy performance parameters of R1234yf in a drop-in replacement are close to those obtained with R134a at high condensing temperatures and making use of an IHX.

\section{ACKNOWLEDGMENTS}

This study was sponsored by Fundació Caixa Castelló-Bancaixa under the project P11B2010-24 "Aplicación de nuevos refrigerantes con bajo potencial de efecto invernadero en sistemas de frío comercial y climatización".

\section{REFERENCES}

Akasaka, R., Tanaka, K., Higashi, Y., 2010. Thermodynamic property modeling for 2,3,3,3tetrafluoropropene (HFO-1234yf). Int. J. Refrigeration 33, 52-60.

Bryson, M., Dixon, C., St Hill, S., 2011. Testing of HFO-1234yf and R152a as mobile air conditioning refrigerant replacements. Ecolibrium May, 30-38.

BSI, 2004. Determination of Explosion Limits of Gases and Vapours. BS EN 1839:2003, The British Standards Institution (BSI), London, UK.

Bolaji, B.O., 2010. Experimental study of R152a and R32 to replace R134a in a domestic refrigerator. Energy 35, 3793-3798. 
Directive 2006/40/EC of The European Parliament and of the Council of 17 May 2006 relating to emissions from air-conditioning systems in motor vehicles and amending Council Directive 70/156/EC. Official J. of the European Union (2006). Retrieved online at http://eurlex.europa.eu/LexUriServ/LexUriServ.do?uri=OJ:L:2006:161:0012:0018:EN:PDF November 8, 2011.

Endoh, K., Matsushima, H., Takaku, S., 2010. Evaluation of Cycle Performance of Room Air Conditioner Using HFO1234yf as Refrigerant. In: Int. Refrig. and Air Cond. Conf. at Purdue, West Lafayette, IN, USA, Paper No. 1050.

Global Environmental Change Report (GCRP), 1997. A Brief Analysis Kyoto Protocol, vol. IX, p. 24.

Henne, S., Shallcross, D.E., Reimann, S., Xiao, P., Brunner, D., O’Doherty, S., Buchmann, B., 2012. Future Emissions and Atmospheric Fate of HFC-1234yf from Mobile Air Conditioners in Europe. Environ. Sci. Technol. 46, 1650-1658.

Koban, M., 2009. HFO-1234yf Low GWP Refrigerant LCCP Analysis. SAE Technical Paper 2009-01-0179, doi: 10.4271/2009-01-0179.

Leck, T.J., 2010. New High Performance, Low GWP Refrigerants for Stationary AC and Refrigeration. In: Int. Refrig. and Air Cond. Conf. at Purdue, West Lafayette, IN, USA, Paper No. 1032.

Lee, Y., Jung, D., 2012. A brief performance comparison of R1234yf and R134a in a bench tester for automobile applications. Appl. Therm. Eng. 35, 240-242. 
Lemmon, E.W., Huber, M.L., McLinden, M.O., 2007. Reference fluid thermodynamic and transport properties (REFPROP), version 8.0, in NIST Standard Reference Database 23.

Gaithersburg, MD: National Institute of Standards and Technology.

Minor, B., Spatz M., 2007. A Low GWP Refrigerant for MAC. Presentation at the 2nd Int. Workshop on Mobile Air Cond. and Auxiliary Syst.

Nielsen, O.J., Javadi, M.S., Sulbak, A., Hurley, M.D., Wallington, T.J., Singh, R., 2007. Atmospheric chemistry of $\mathrm{CF} 3 \mathrm{CF}=\mathrm{CH} 2$ : Kinetics and mechanisms of gas-phase reactions with $\mathrm{Cl}$ atoms, $\mathrm{OH}$ radicals, and O3. Chem. Phys. Lett. 439, 18-22.

Okazaki, T., Maeyama, H., Saito, M., Yamamoto, T., 2010. Performance and Reliability Evaluation of a Room Air Conditioner with Low GWP Refrigerant. In: Int. Symp. on Nextgeneration Air Cond. and Refrig. Technol. Tokyo, Japan.

Papadimitriou, V.C., Talukdar, R.K., Portmann, R.W., Ravishankara, A.R., Burkholder, J.B., 2008. $\mathrm{CF} 3 \mathrm{CF}=\mathrm{CH} 2$ and $(\mathrm{Z})-\mathrm{CF} 3 \mathrm{CF}=\mathrm{CHF}$ : Temperature dependent $\mathrm{OH}$ rate coefficients and global warming potentials. Phys. Chem. Chem. Phys. 10, 808-820.

Reasor, P., Aute, V., Radermacher, R., 2010. Refrigerant R1234yf Performance Comparison Investigation. In: Int. Refrig. and Air Cond. Conf. at Purdue, West Lafayette, IN, USA, Paper No. 1085.

Spatz, M. and Minor, B., 2008. HFO-1234yf: A low GWP refrigerant for MAC. VDA Alternative refrigerant. Winter Meeting. Saalfelden, Australia.

Taylor, J.R., 1997. An introduction to error analysis. 2nd ed. Sausalito: University Science Books. 
UNEP, 1987. Montreal Protocol on Substances that Deplete the Ozone Layer. Final Act. United Nations, New York.

Wongwises, S., Kamboon A., Orachon, B., 2006. Experimental investigation of hydrocarbon mixtures to replace HFC-134a in an automotive air conditioning system. Energy Convers. Manage 47, 1644-1659.

World Meteorological Organization (WMO), 2007. Scientific Assessment of Ozone Depletion: 2006, Global Ozone, Research and Monitoring Project - Report 50, Geneva, Switzerland.

Zilio, C., Brown, J.S., Schiochet G., Cavallini, A., 2011. The refrigerant R1234yf in air conditioning systems. Energy 36, 6110-6120. 


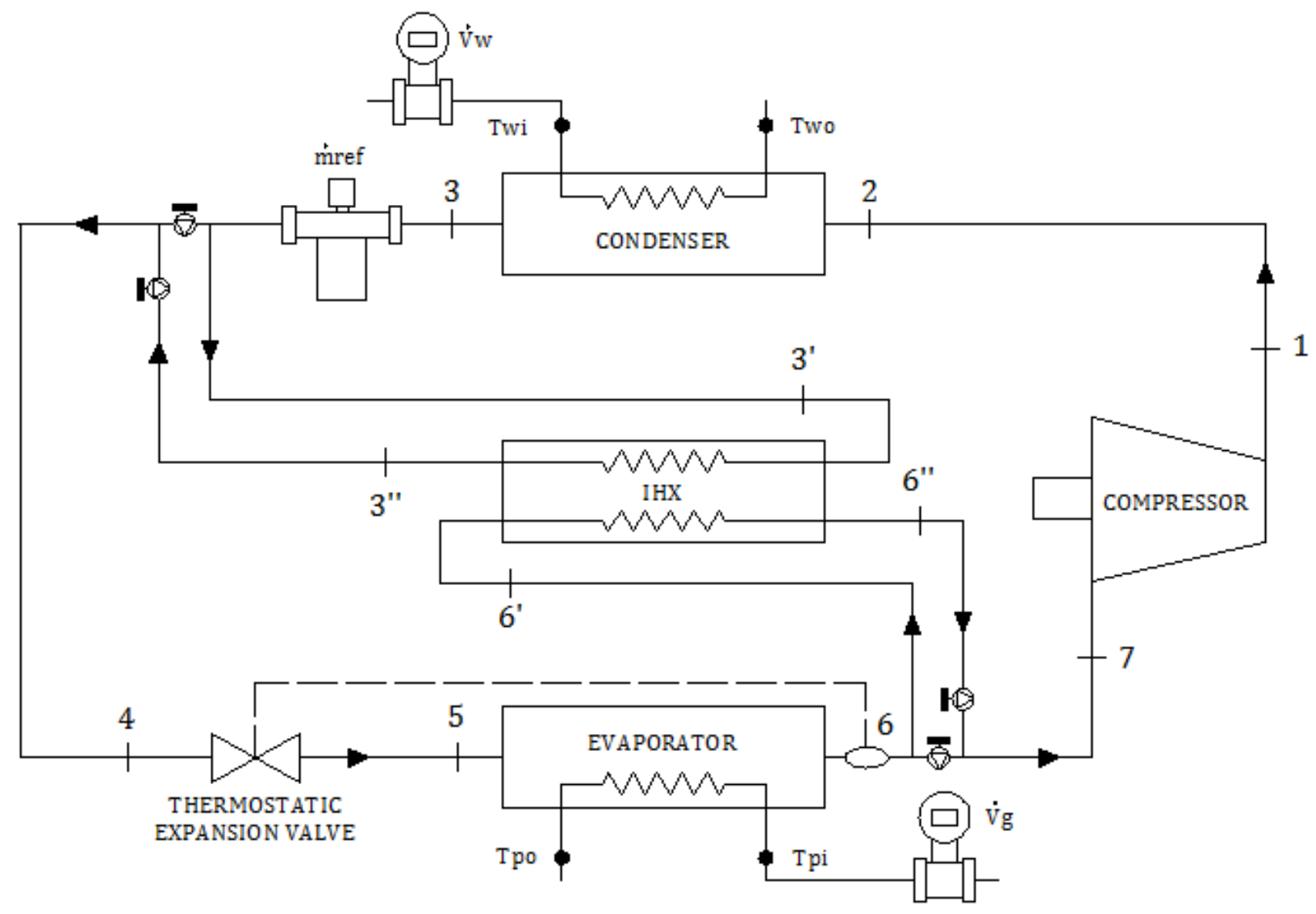

Fig. 1. Schematic diagram of the test bench. 


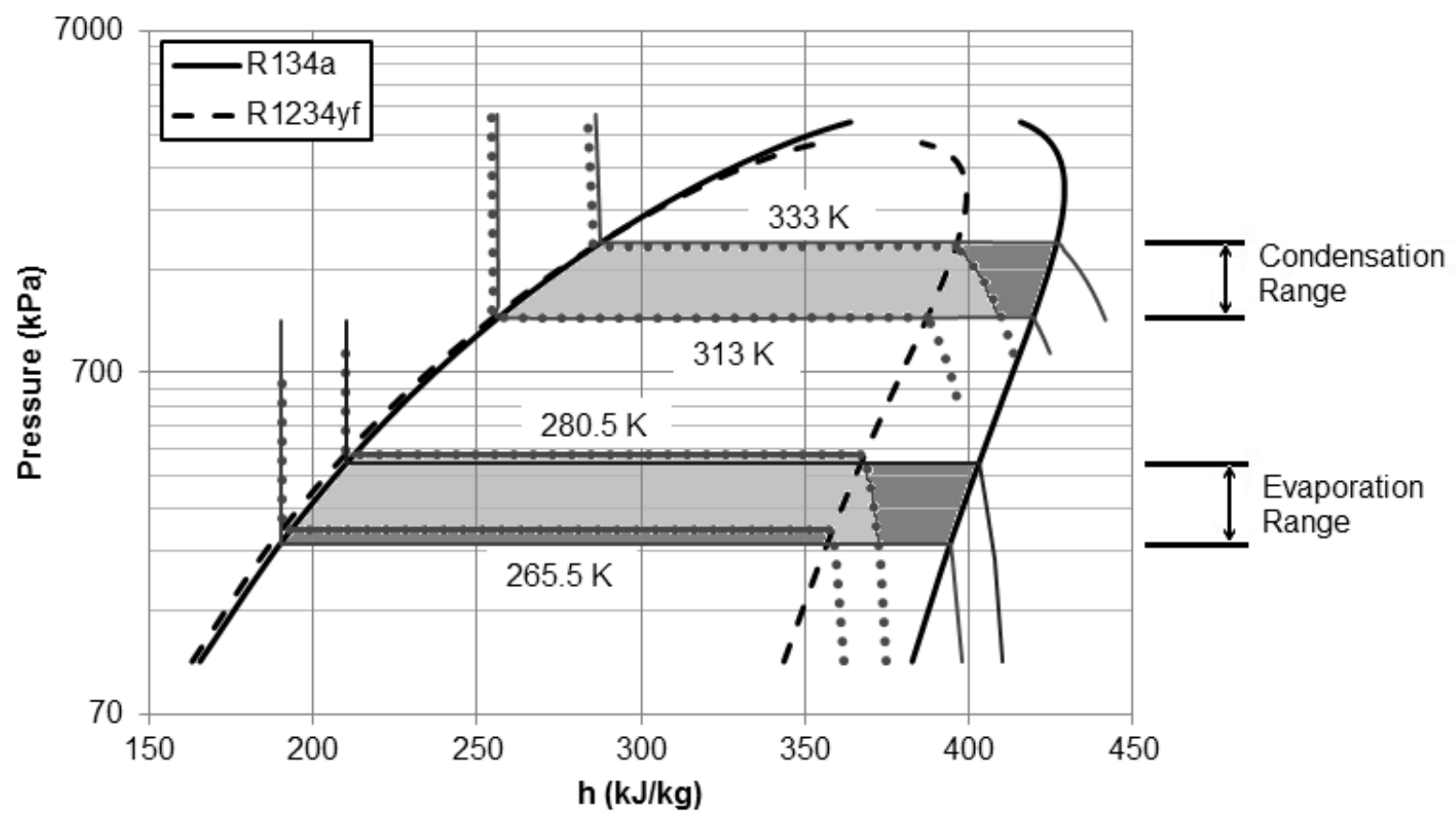

Fig. 2. Experimental test variation range. 


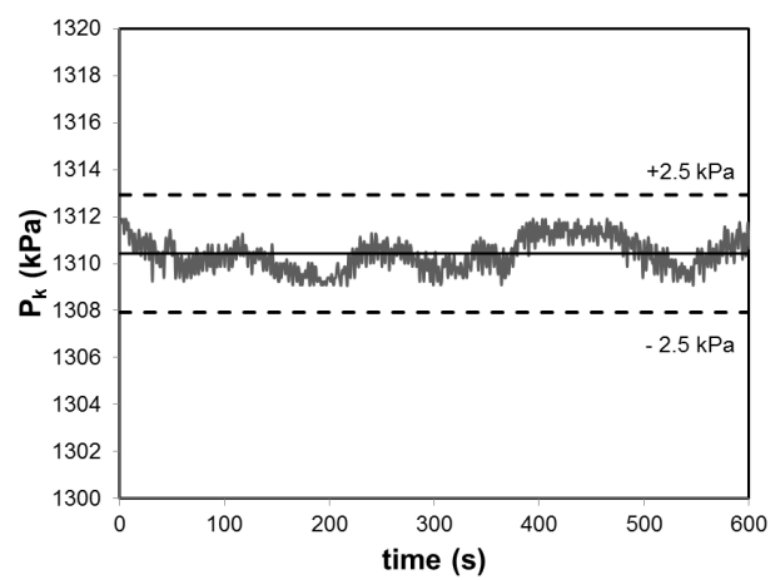

(a)

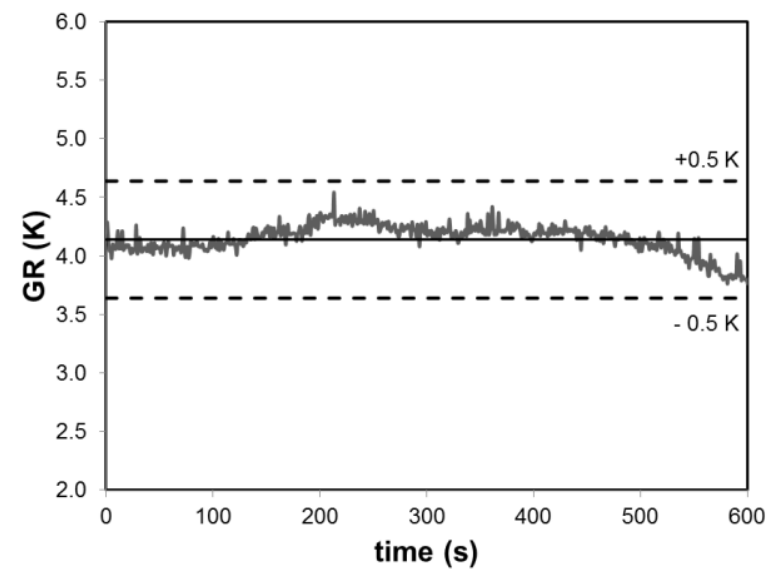

(c)

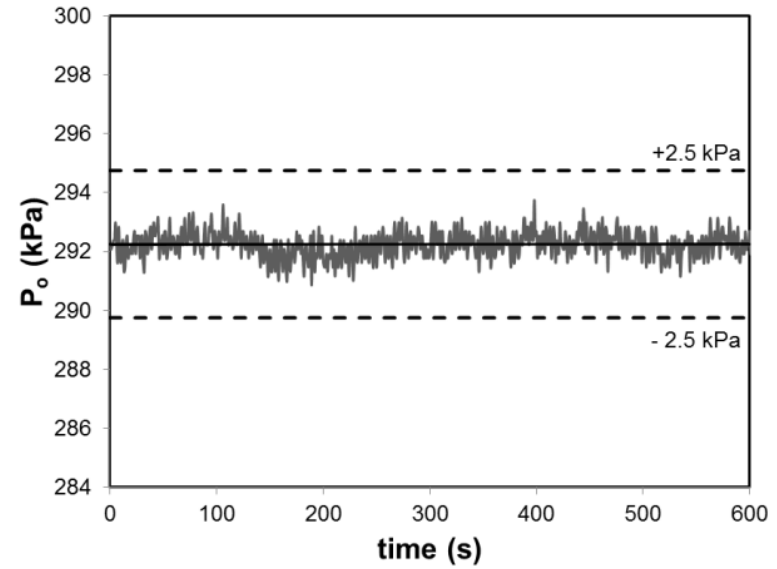

(b)

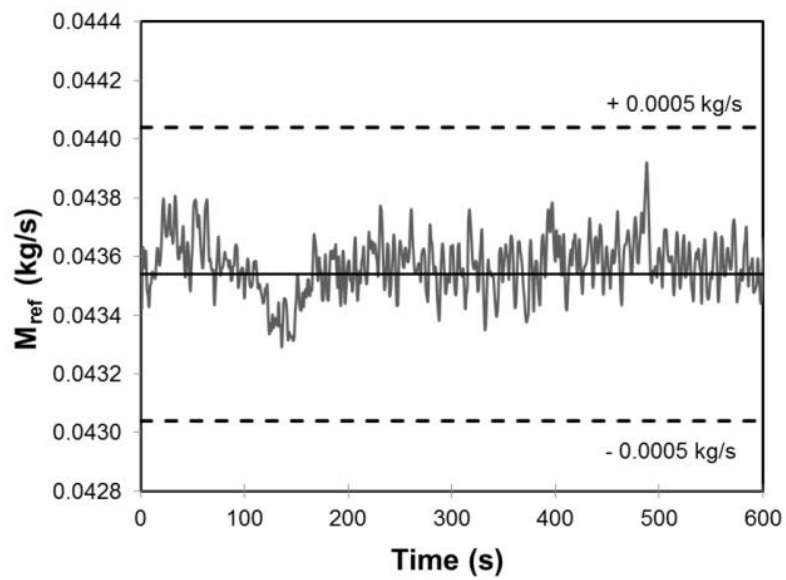

(d)

Fig. 3. Fluctuation of operating parameters in a random steady-state test. (a) Condensing pressure, (b) evaporating pressure, (c) superheating degree, (d) refrigerant mass flow rate. 


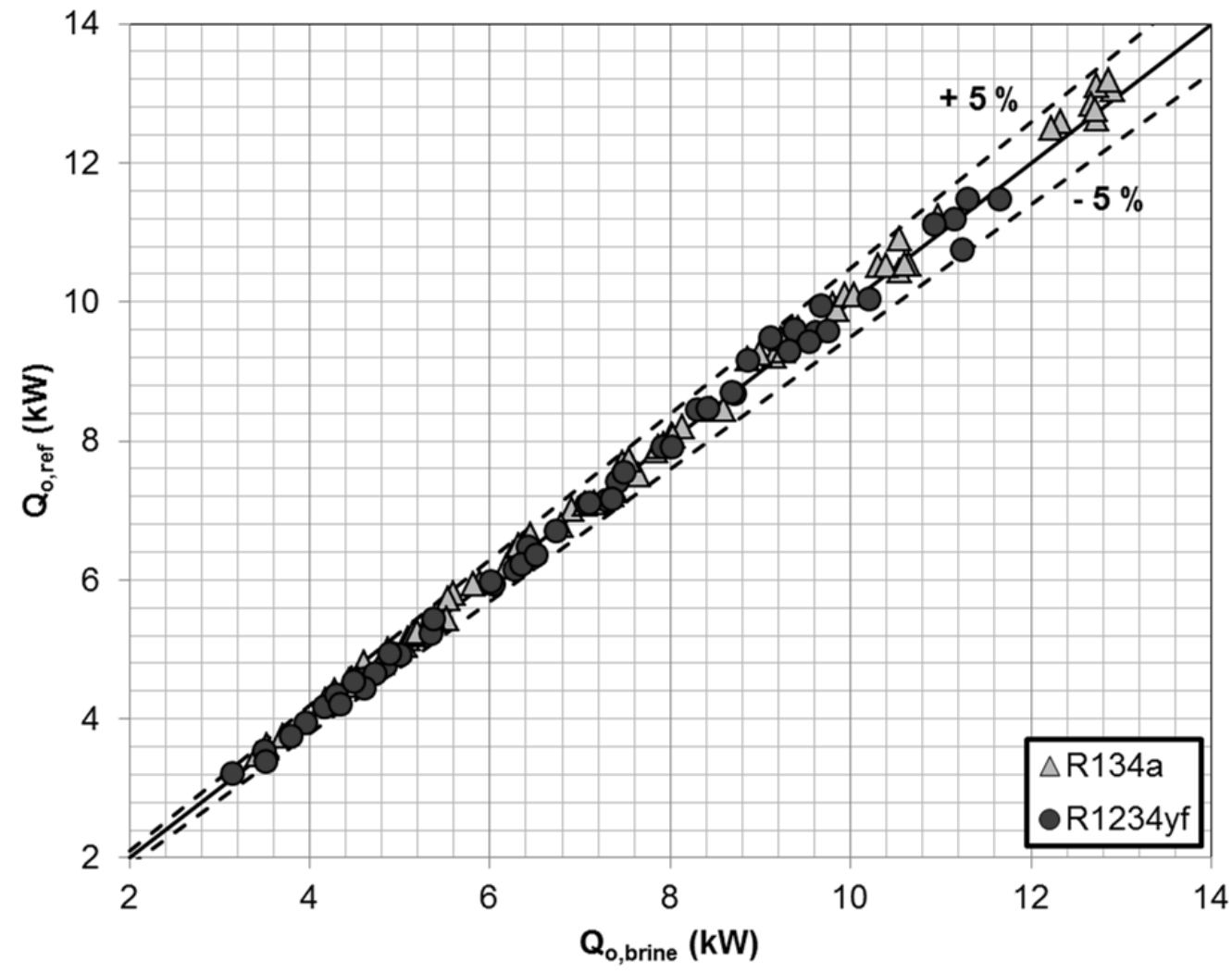

Fig. 4. Cooling capacity at the evaporator (comparing refrigerant side and brine side). 


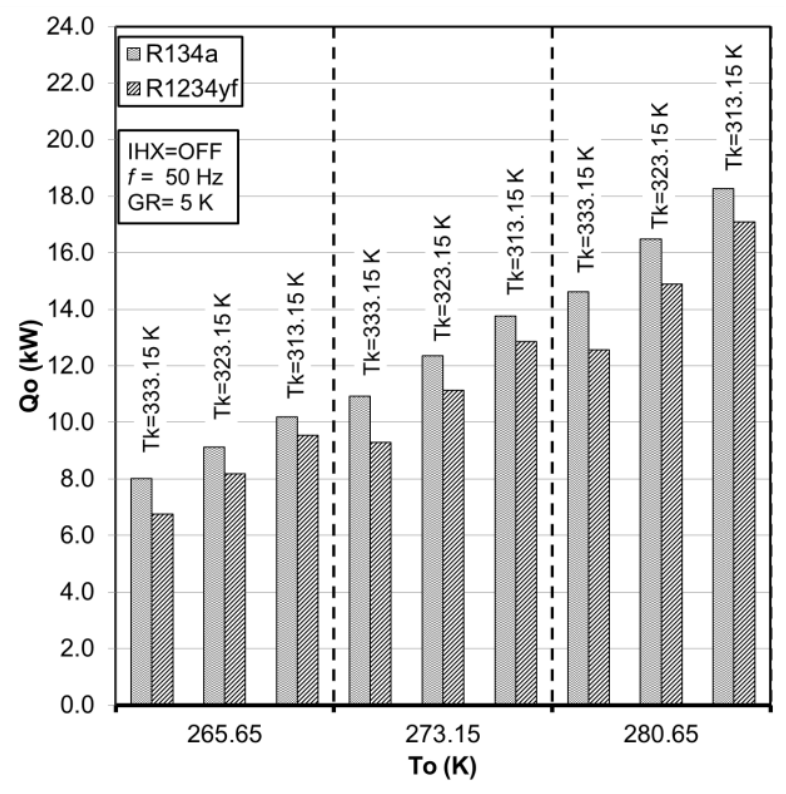

(a)

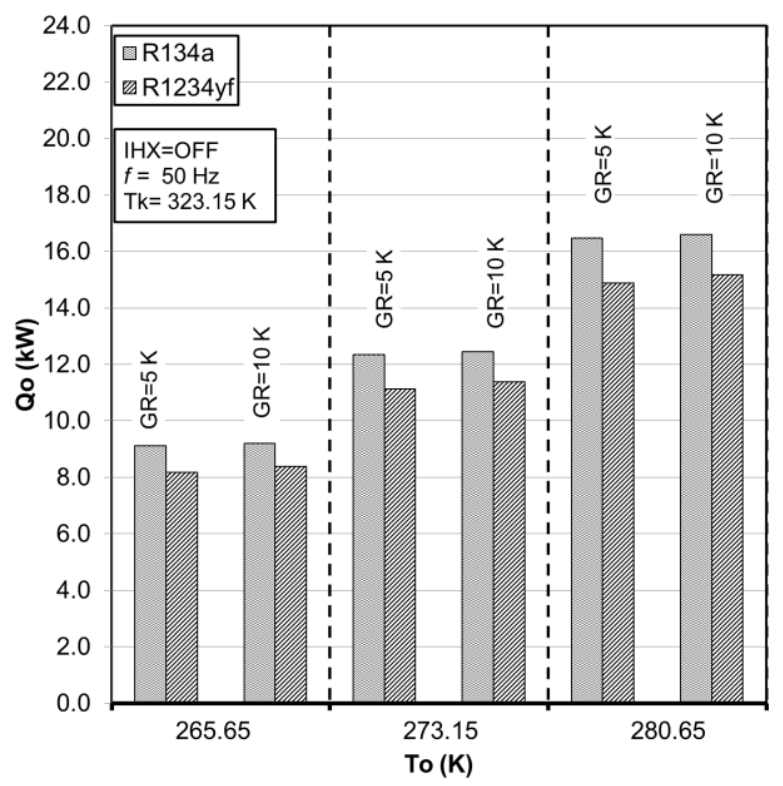

(c)

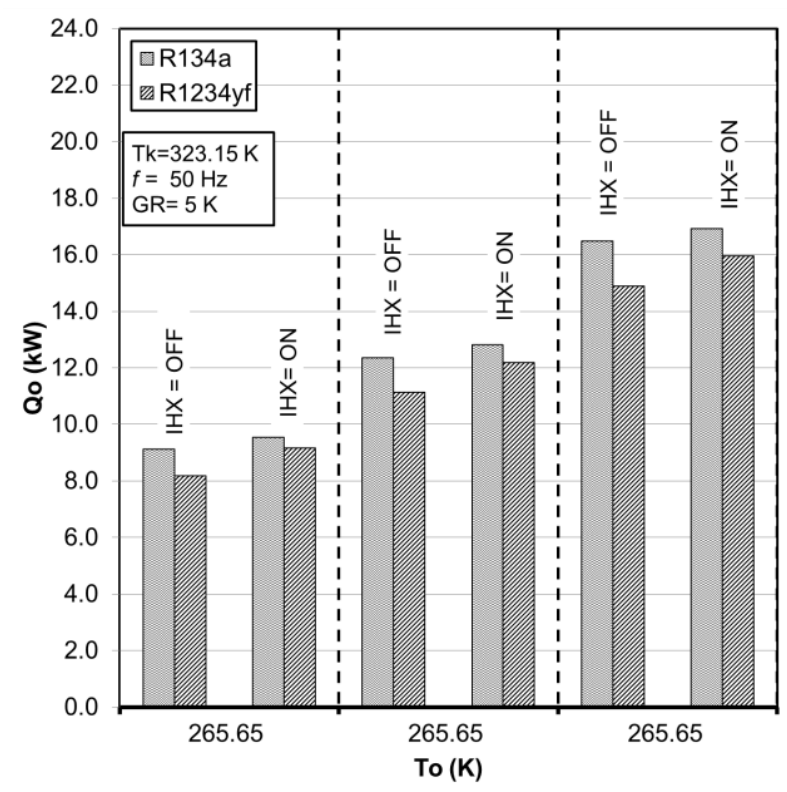

(b)

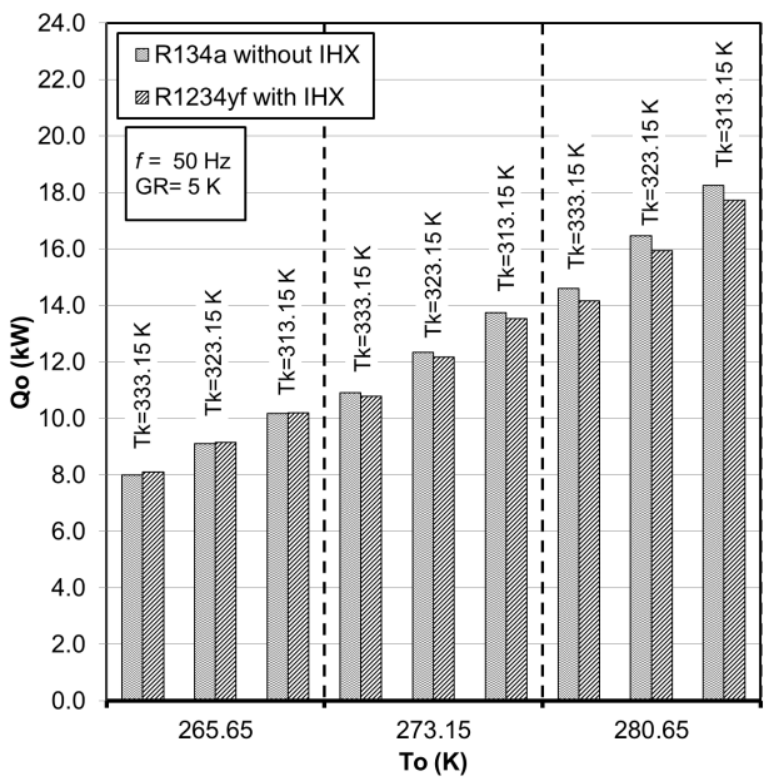

(d)

Fig. 5. Theoretical cooling capacity variation versus evaporating temperature $T_{o}$ varying: (a) condensing temperature, (b) with and without IHX (c) varying superheating degree, (d) comparing R1234yf with IHX and R134a without IHX. 


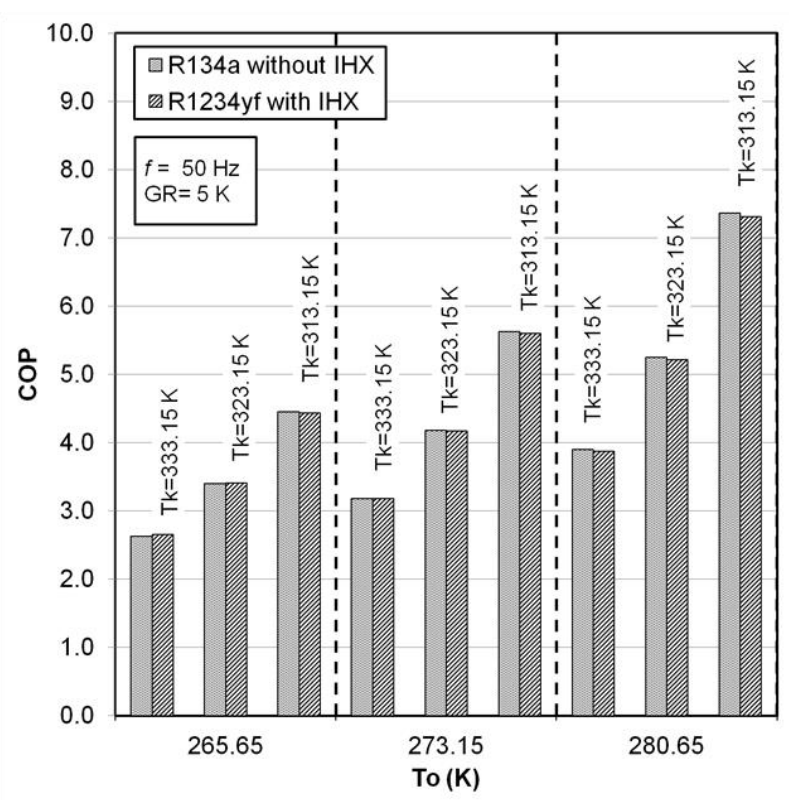

(a)

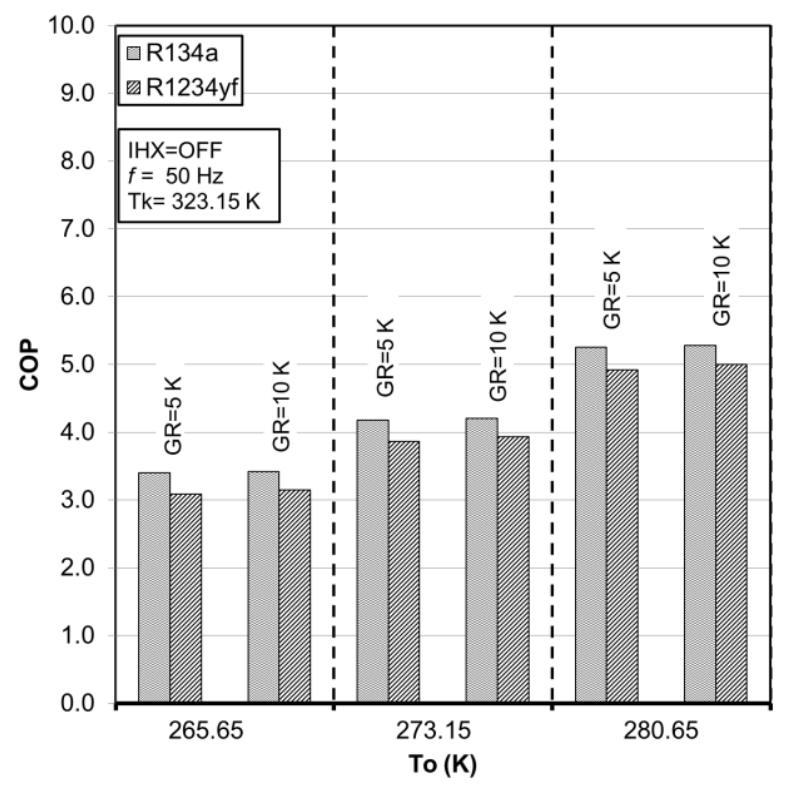

(c)

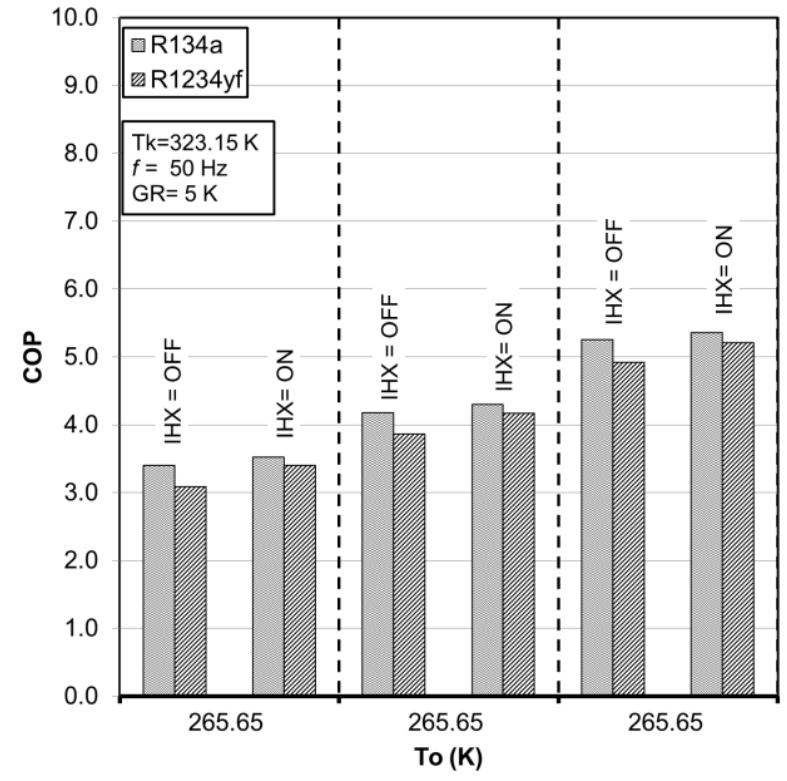

(b)

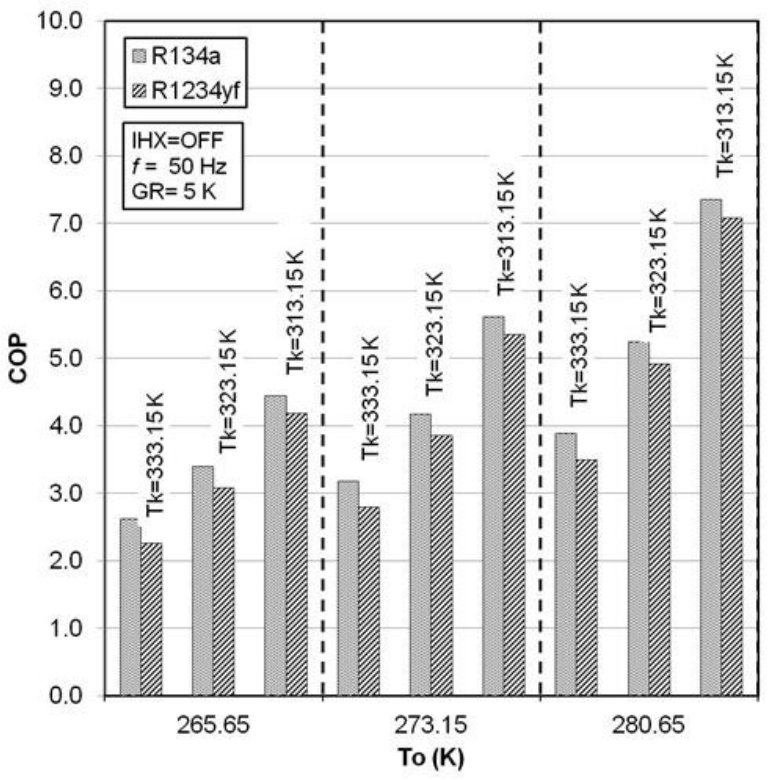

(d)

Fig. 6. Theoretical COP variation versus evaporation temperature $T_{o}$ varying: (a) condensing temperature, (b) with and without IHX (c) varying superheating degree, (d) comparing R1234yf with IHX and R134a without IHX. 


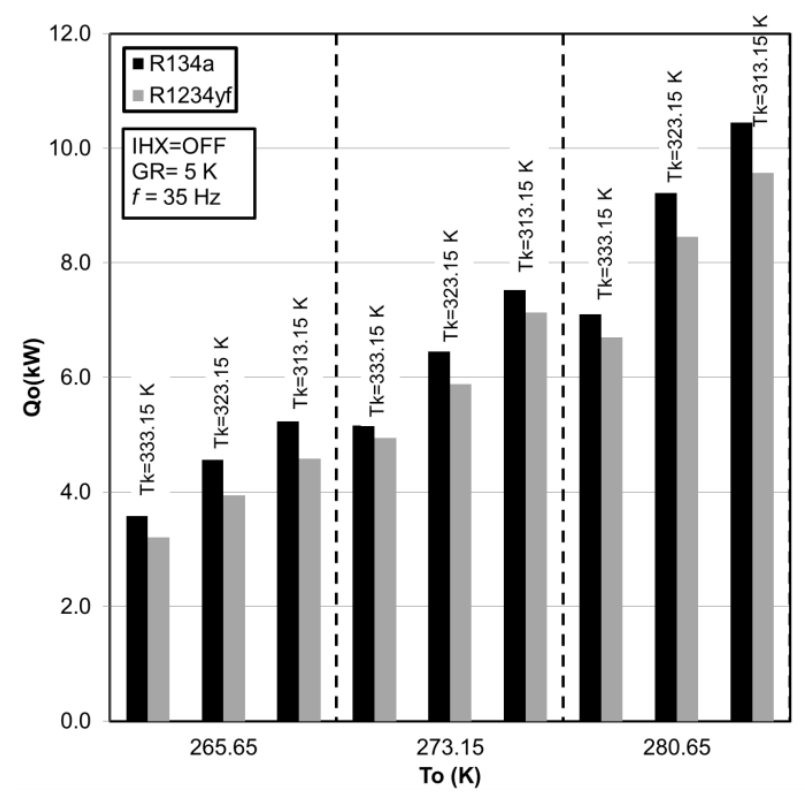

(a)

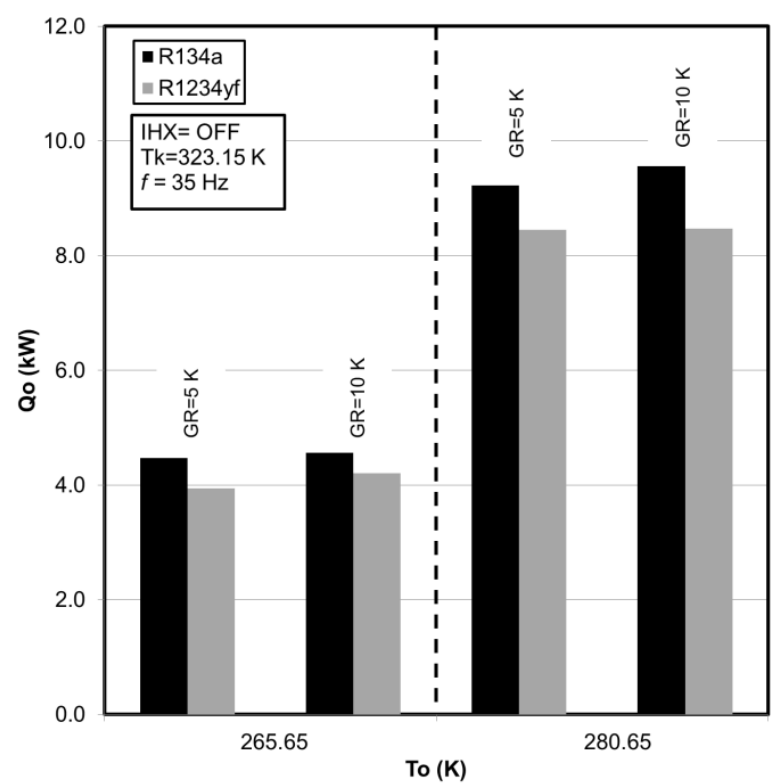

(c)

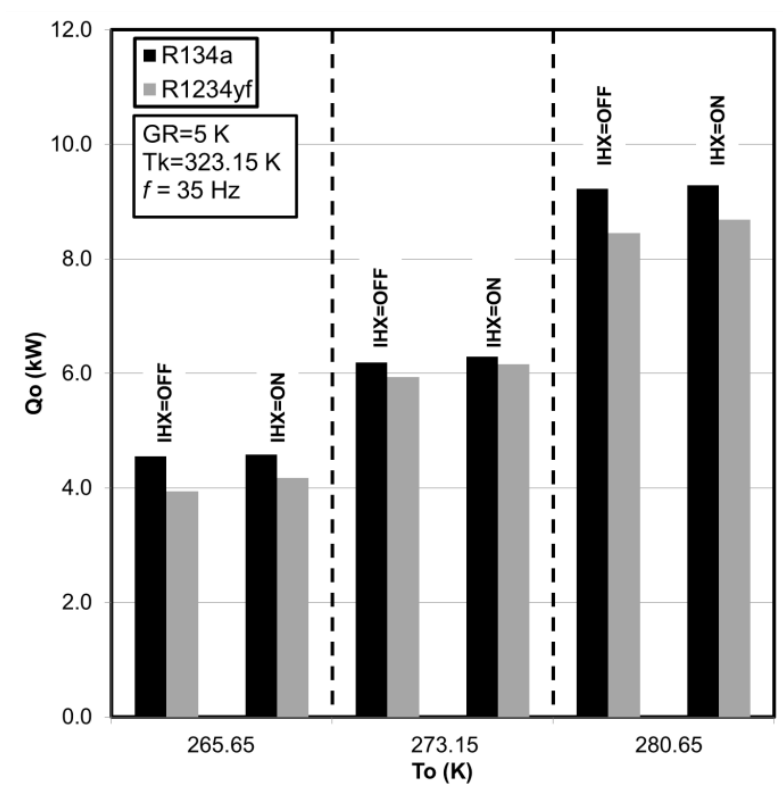

(b)

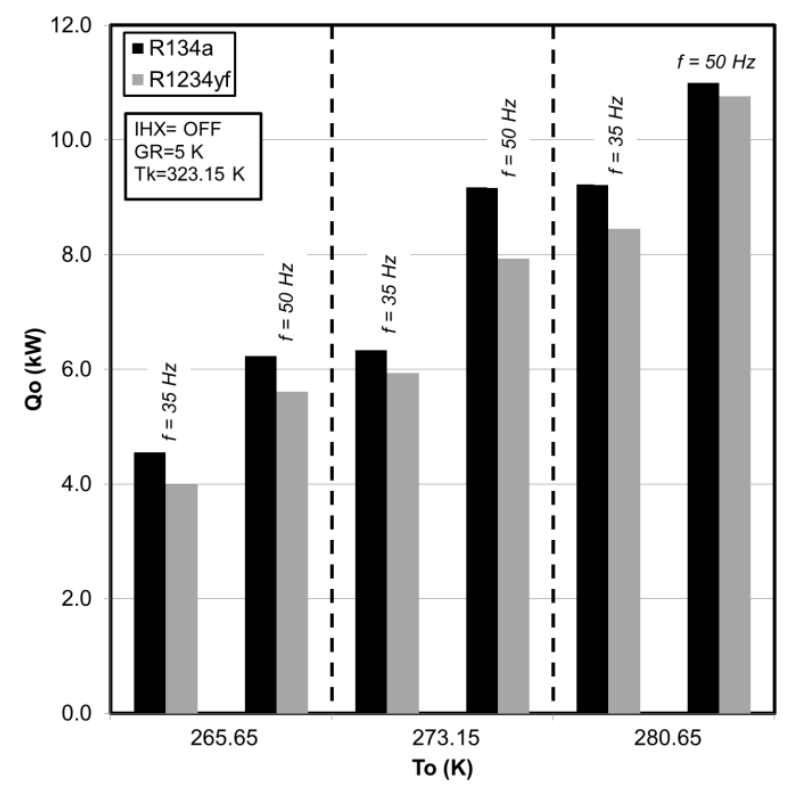

(d)

Fig. 7. Experimental cooling capacity variation regarding evaporating temperature $T_{o}$ varying:

(a) condensing temperature, (b) subcooling degree, (c) superheating degree, (d) compressor drive frequency. 


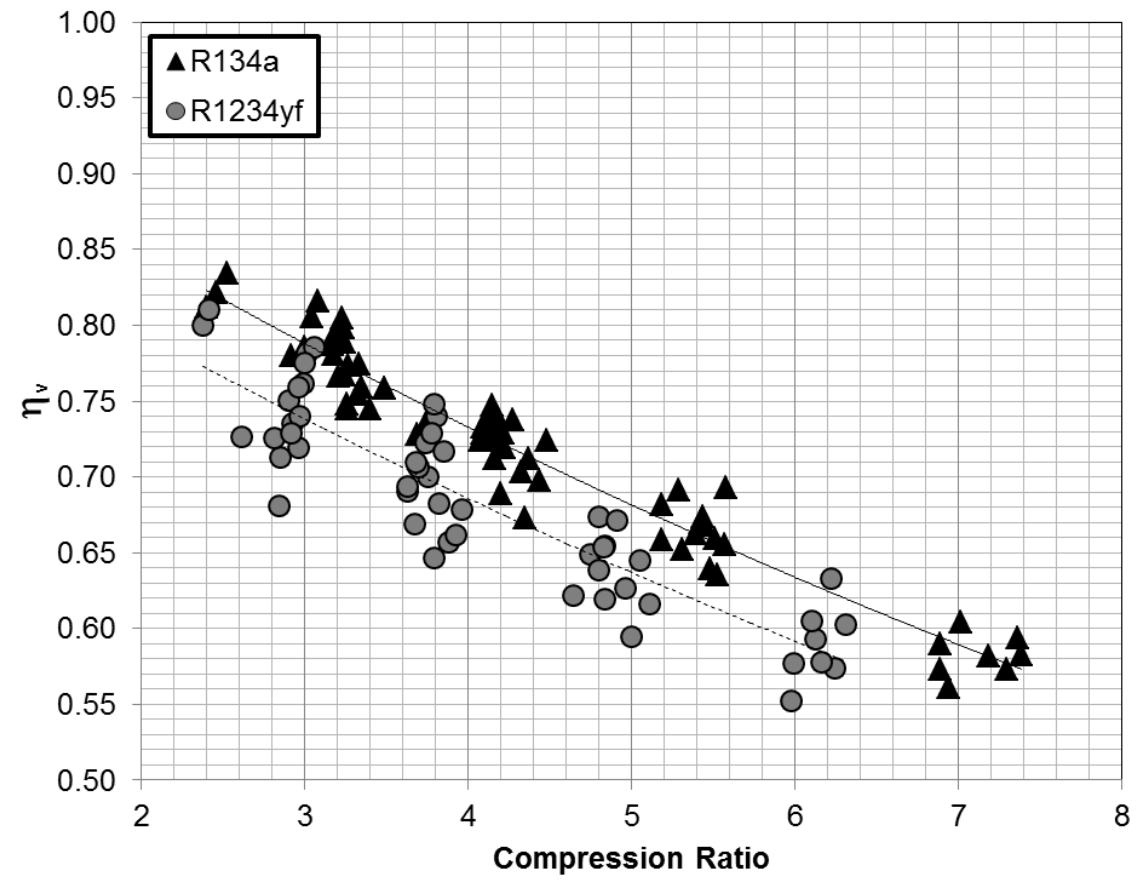

Fig. 8. R134a and R1234yf volumetric efficiency versus compression ratio. 


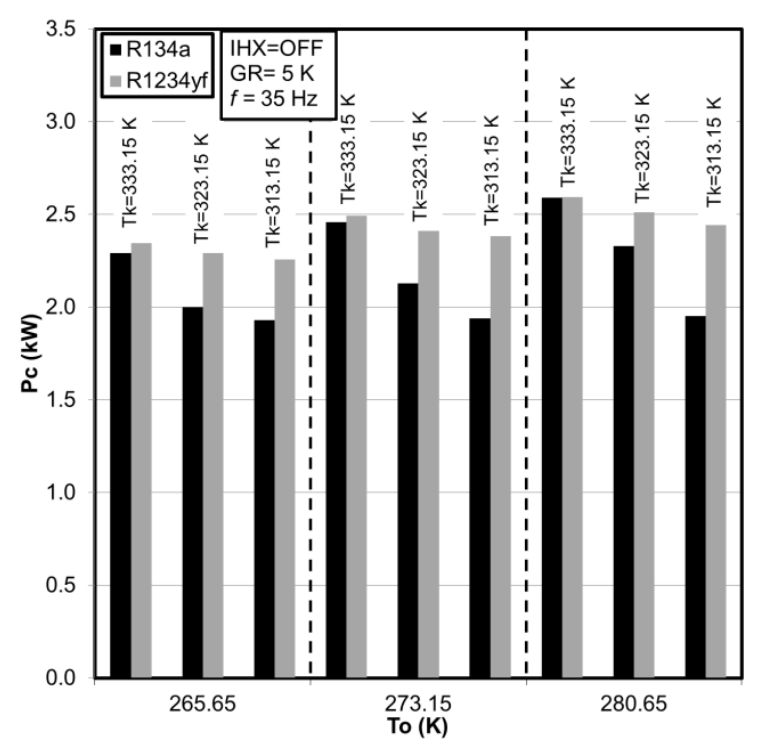

(a)

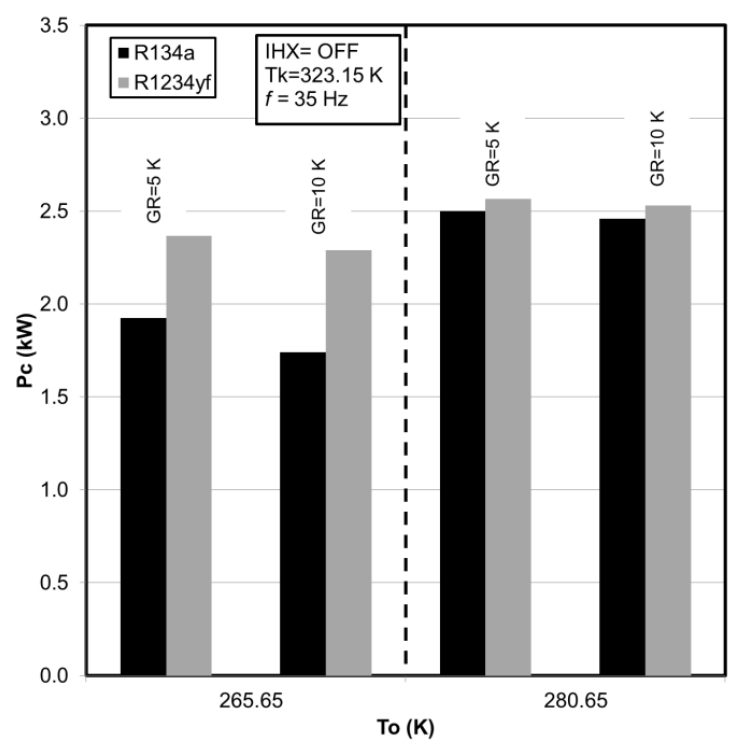

(b)

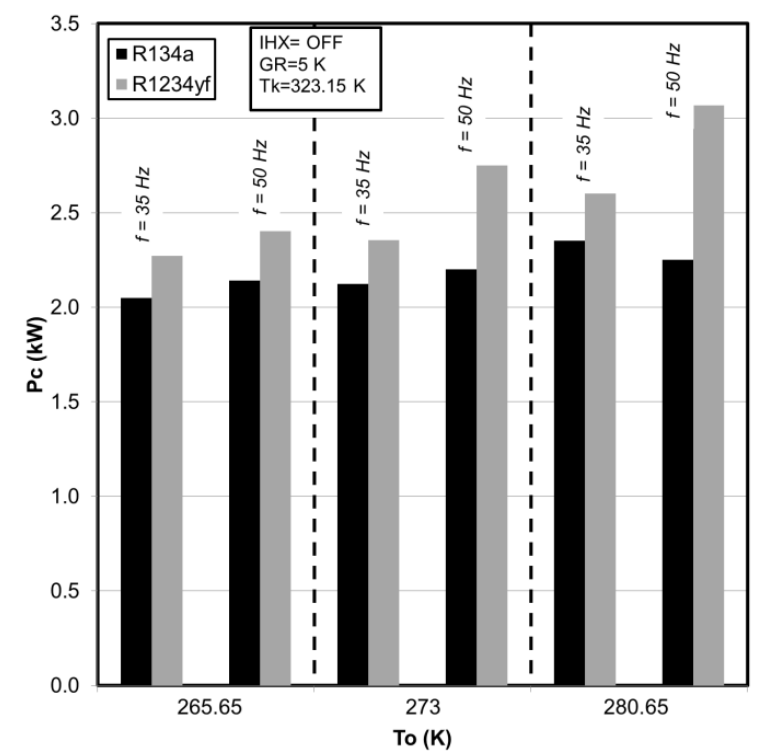

(c)

Fig. 9. Experimental power consumption $\left(P_{c}\right)$ regarding evaporation temperature $T_{o}$ varying: (a) condensing temperature, (b) superheating degree, (c) compressor drive frequency. 


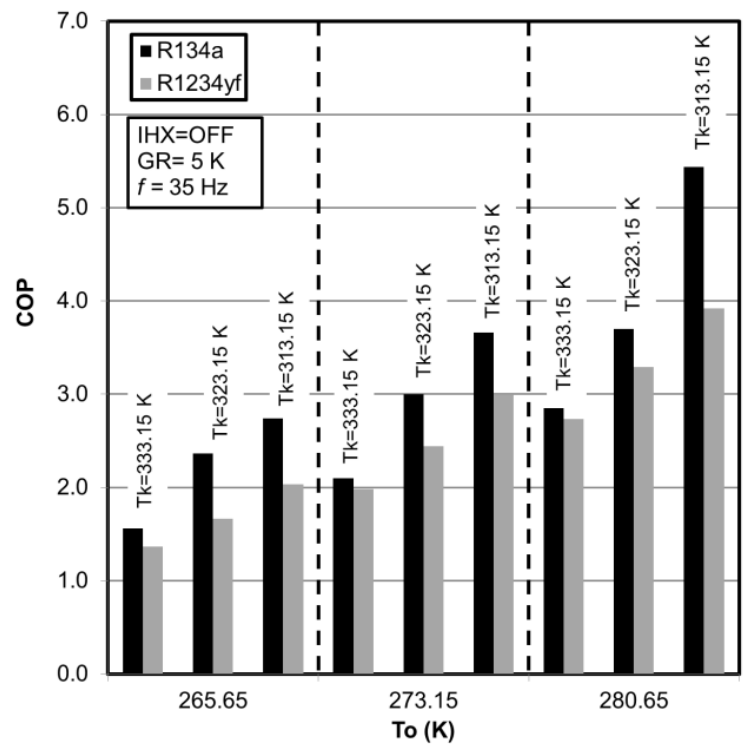

(a)

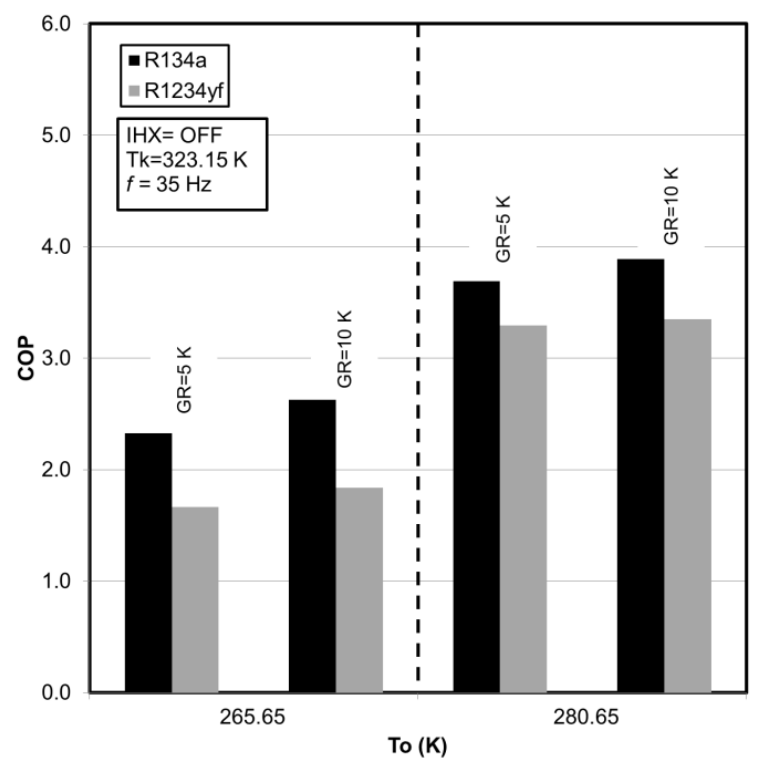

(c)

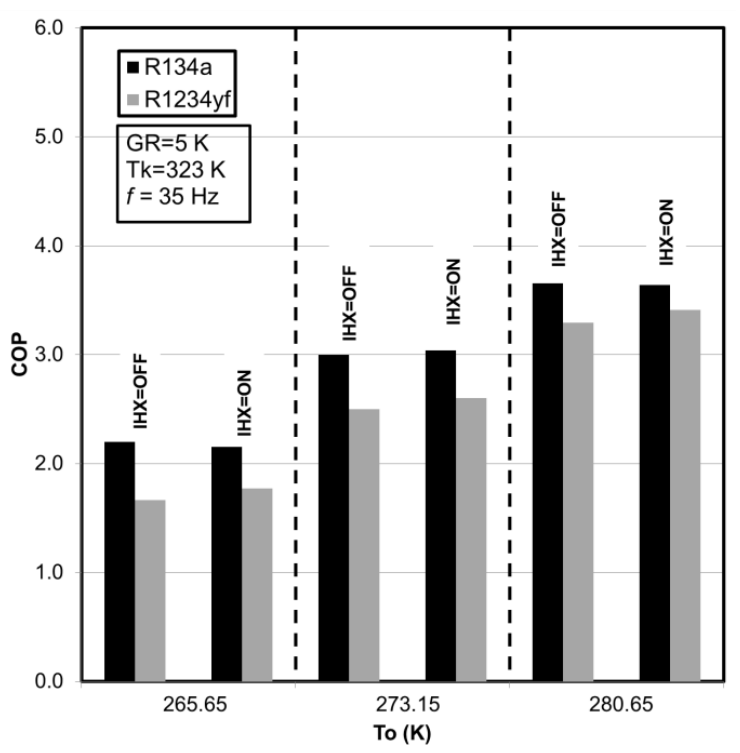

(b)

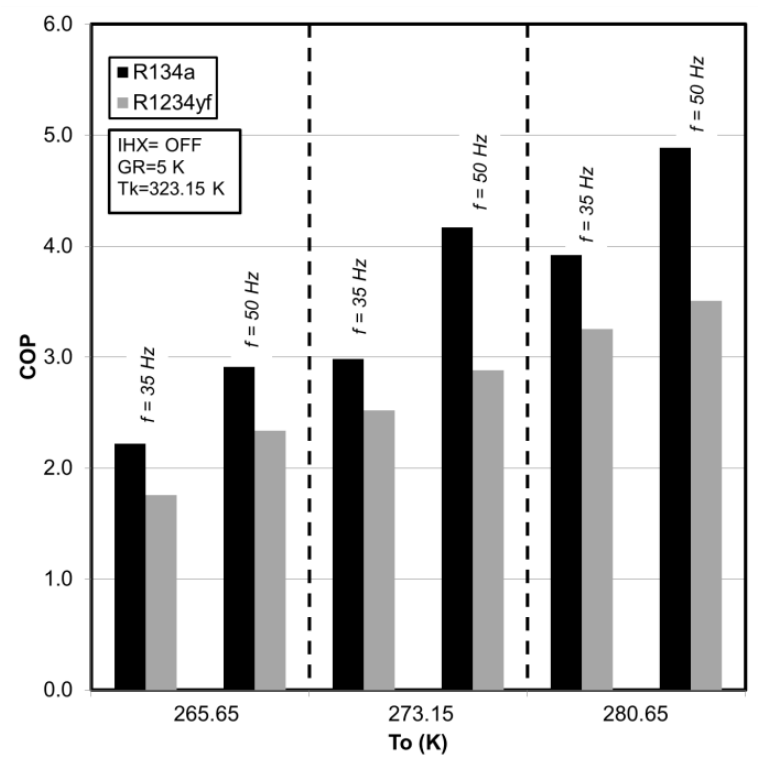

(d)

Fig. 10. Experimental COP variation regarding evaporation temperature $T_{o}$ varying: (a) condensing temperature, (b) use of IHX, (c) superheating degree, (d) compressor drive frequency. 


\section{FIGURE CAPTIONS}

Fig. 1. Schematic diagram of the test bench.

Fig. 2. Experimental test variation range.

Fig. 3. Fluctuation of operating parameters in a random steady-state test. (a) Condensing pressure, (b) evaporating pressure, (c) superheating degree, (d) refrigerant mass flow rate.

Fig. 4. Cooling capacity at the evaporator (comparing refrigerant side and brine side).

Fig. 5. Theoretical cooling capacity variation versus evaporation temperature $T_{o}$ varying: (a) condensing temperature, (b) subcooling degree, (c) superheating degree, (d) compressor drive frequency.

Fig. 6. Theoretical COP variation versus evaporation temperature $T_{o}$ varying: (a) condensing temperature, (b) subcooling degree, (c) superheating degree, (d) compressor drive frequency.

Fig. 7. Experimental cooling capacity variation regarding evaporating temperature $T_{o}$ varying: (a) condensing temperature, (b) subcooling degree, (c) superheating degree, (d) compressor drive frequency.

Fig. 8. R134a and R1234yf volumetric efficiency versus compression ratio. 
Fig. 9. Experimental power consumption $\left(P_{c}\right)$ regarding evaporation temperature $T_{o}$ varying: (a) condensing temperature, (b) superheating degree, (c) compressor drive frequency.

Fig. 10. Experimental COP variation regarding evaporation temperature $T_{o}$ varying: (a) condensing temperature, (b) use of IHX, (c) superheating degree, (d) compressor drive frequency. 
Table 1. Range of operating conditions in the experimental tests.

\begin{tabular}{lr}
\hline Controlled parameters & Range values \\
\hline Condensation temperature $\left(T_{k}\right)$ & $313.15-333.15(\mathrm{~K})$ \\
Evaporation temperature $\left(T_{o}\right)$ & ON/OFF \\
Use of IHX & $5-10(\mathrm{~K})$ \\
Superheating degree $(G R)$ & $35-50(\mathrm{~Hz})$ \\
Compressor drive frequency $(f)$ & \\
\hline
\end{tabular}


Table 2. Uncertainties for calculated parameters.

\begin{tabular}{lccc}
\hline & $\mathbf{Q}_{\mathbf{0}}(\mathbf{k W})$ & $\mathbf{C O P}$ & $\mathbf{\eta}_{\mathbf{v}}$ \\
\hline Experimental & $0.60 \%$ & $0.74 \%$ & $1.01 \%$ \\
estimation & & & \\
\hline
\end{tabular}


Table 3. Experimental variation for cooling capacity, compressor power consumption and COP taking R134a as baseline.

\begin{tabular}{|c|c|c|c|c|c|c|c|c|c|}
\hline$T_{o}(\mathrm{~K})$ & $T_{k}(\mathbf{K})$ & $\% Q_{o, \text { exp }}=$ & $=\frac{Q_{o, \mathrm{R} 134 \mathrm{a}}-Q_{o, \mathrm{R} 1234 \mathrm{yi}}}{Q_{o, \mathrm{R} 13 \mathrm{ad}}}$ & $\times 100$ & $\% P_{c, \text { exp }}=$ & $=\frac{P_{c, \mathrm{R} 134 \mathrm{a}}-P_{c, \mathrm{R} 123 \mathrm{yf}}}{P_{c, \mathrm{R} 134 \mathrm{a}}}$ & $f \times 100$ & $\% C O P_{\text {epp }}=$ & 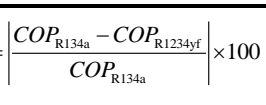 \\
\hline 265.65 & 333.15 & & $10.32 \%$ & & & $2.34 \%$ & & & $12.37 \%$ \\
\hline 265.65 & 323.15 & & $13.46 \%$ & & & $14.47 \%$ & & & $24.40 \%$ \\
\hline 265.65 & 313.15 & & $12.37 \%$ & & & $18.24 \%$ & & & $25.82 \%$ \\
\hline 273.15 & 333.15 & & $4.36 \%$ & & & $1.32 \%$ & & & $5.60 \%$ \\
\hline 273.15 & 323.15 & & $8.85 \%$ & & & $12.53 \%$ & & & $19.00 \%$ \\
\hline 273.15 & 313.15 & & $5.27 \%$ & & & $24.38 \%$ & & & $23.84 \%$ \\
\hline 280.65 & 333.15 & & $5.68 \%$ & & & $0.15 \%$ & & & $5.82 \%$ \\
\hline 280.65 & 323.15 & & $8.36 \%$ & & & $9.23 \%$ & & & $16.11 \%$ \\
\hline 280.65 & 313.15 & & $8.39 \%$ & & & $27.03 \%$ & & & $27.89 \%$ \\
\hline$T_{o}$ & $I H X$ & $\% Q_{o, \text { exp }}=$ & 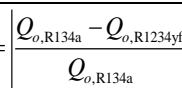 & $\times 100$ & $\% P_{c, \text { exp }}=$ & 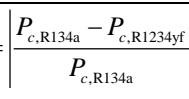 & $\mid \times 100$ & $\% C O P_{\text {exp }}=$ & 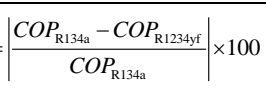 \\
\hline 265.65 & OFF & & $13.46 \%$ & & & $14.34 \%$ & & & $24.31 \%$ \\
\hline 265.65 & $\mathrm{ON}$ & & $8.98 \%$ & & & $10.18 \%$ & & & $17.39 \%$ \\
\hline 273.15 & OFF & & $8.85 \%$ & & & $12.53 \%$ & & & $19.00 \%$ \\
\hline 273.15 & $\mathrm{ON}$ & & $7.40 \%$ & & & $10.77 \%$ & & & $16.41 \%$ \\
\hline 280.65 & OFF & & $8.36 \%$ & & & $3.03 \%$ & & & $11.05 \%$ \\
\hline 280.65 & $\mathrm{ON}$ & & $6.47 \%$ & & & $0.19 \%$ & & & $6.65 \%$ \\
\hline
\end{tabular}




\begin{tabular}{|c|c|c|c|c|c|c|c|c|c|}
\hline$T_{o}$ & $G R$ & $\% Q_{o, \mathrm{exp}}=$ & $=\left|\frac{Q_{o, \mathrm{R} 13 \mathrm{a}}-Q_{o, \mathrm{R} 1324 \mathrm{yf}}}{Q_{o, \mathrm{R} \text { I3 } 3 \mathrm{a}}}\right|$ & $\times 100$ & $\% P_{c, \exp }=$ & $=\frac{P_{c, \mathrm{R} 134 \mathrm{a}}-P_{c, \mathrm{R} 123 \mathrm{y} \mathrm{fi}}}{P_{c, \mathrm{R} 134 \mathrm{a}}}$ & $\times 100$ & $\% C O P_{\text {exp }}=$ & 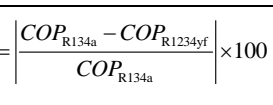 \\
\hline 265.65 & 5 & & $13.46 \%$ & & & $22.99 \%$ & & & $29.64 \%$ \\
\hline 265.65 & 10 & & $8.51 \%$ & & & $31.67 \%$ & & & $30.52 \%$ \\
\hline 280.65 & 5 & & $8.36 \%$ & & & $3.03 \%$ & & & $11.05 \%$ \\
\hline 280.65 & 10 & & $11.40 \%$ & & & $2.42 \%$ & & & $13.49 \%$ \\
\hline$T_{o}$ & $f$ & $\% Q_{o, \exp }=$ & 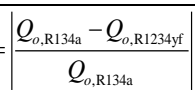 & $\times 100$ & $\% P_{c, \exp }=$ & $=\frac{P_{c, \mathrm{R} 134 \mathrm{a}}-P_{c, \mathrm{R} 123 \mathrm{~A} 4 \mathrm{f}}}{P_{c, \mathrm{R} 13 \mathrm{3a}}}$ & $f \times 100$ & $\% C O P_{\text {exp }}=$ & 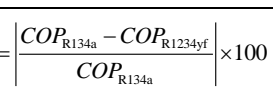 \\
\hline 265.65 & 35 & & $13.46 \%$ & & & $11.11 \%$ & & & $22.12 \%$ \\
\hline 265.65 & 50 & & $13.83 \%$ & & & $10.86 \%$ & & & $22.28 \%$ \\
\hline 273.15 & 35 & & $8.85 \%$ & & & $12.53 \%$ & & & $19.00 \%$ \\
\hline 273.15 & 50 & & $13.82 \%$ & & & $24.59 \%$ & & & $30.83 \%$ \\
\hline 280.65 & 35 & & $8.36 \%$ & & & $9.23 \%$ & & & $16.11 \%$ \\
\hline 280.65 & 50 & & $2.16 \%$ & & & $33.28 \%$ & & & $26.59 \%$ \\
\hline
\end{tabular}

